\title{
The Complex Interactions between Cities and Nature
}

\author{
DOI: 10.12776/QIP.V21I1.781
}

\author{
Dani Broitman, Danny Czamanski, Marina Toger
}

Received: 9 September 2016 Accepted: 15 September 2016 Published: 30 April 2017

\begin{abstract}
Purpose: Proximity to nature is highly valued by urbanites. They demonstrate higher willingness to pay for housing at locations near open and green spaces. But, nature in cities can generate negative externalities as well. The aim of this paper is to present the complex relationship between nature and cities and the possible negative influence of urban nature on property prices.
\end{abstract}

Methodology/Approach: The data presented in this paper include open spaces, the presence of wild animals and residential property values in Haifa, Israel. These data were analyzed to uncover spatial regularities and basic statistical relationships.

Findings: The results reveal the expected presence of dominant positive externalities related to proximity to open and green areas. However, in certain areas and under certain circumstances, the nuisances generated by the presence of wild animals in close proximity to housing are correlated with lower property prices.

Research Limitation/implication: We demonstrate in this paper that that there is a complex relationship between nature and cities, albeit focusing our analysis on large mammals in cities only. Disentangling positive and negative externalities of urban nature is a challenging task. The paper presents an example of the potential difficulties that need to be dealt with in such analysis.

Originality/Value of paper: Through the case study, we show that there are good reasons to believe that there are both positive and negative externalities of nature in cities. To our best knowledge, attempts to disentangle both types of effects using property values do not exist in the literature.

Category: Research paper

Keywords: urban nature; property prices; positive and negative externalities; disentangling 


\section{INTRODUCTION}

Traditional analysis of urban spatial evolution has been carried out at a crude geographic resolution and by means of coarse statistical data. Until recently cities tended to be viewed as continuous built up areas with little room for nature. Population growth in cities was presumed to cause the outer boundaries of urban built areas to expand into the surrounding countryside. All open areas within urban boundaries were presumed to be conscripted for and eliminated by infilling and by building waves around cities (Czamanski, Malkinson and Toger, 2014). Urban nature was viewed as an oxymoron. But, contrary to these crude analyses, cities are porous. In between buildings, there are back yards, private and public gardens and lots that are yet to be developed. Studies of urban clusters, defined as continuous built spaces (Benguigui, et al., 2000; 2001a; 2001b; 2004) carried out at a fine spatial resolution, confirm that while open spaces in cities do shrink in quantity, they persist and in the limit represent about a third of the urban land area. More importantly, their connectivity at least in some cities is robust (Czamanski, Malkinson and Toger, 2014; Toger, et al., 2015).

Open spaces in cities are highly appreciated by urbanites as well as have an intrinsic ecological value (Niemelä, 1999; McPhearson, et al., 2016). The proximity to greenspaces has been shown to improve human wellbeing and health (Tzoulas, et al., 2007). However, in addition to the positive externalities that they generate by producing ecosystem services, proximity to nature can generate negative externalities as well. In this paper, we add specific analysis to sharpen the consensus (McPhearson, et al., 2016) that the relationship between cities and nature is quite complex. Their balance is time and location specific. There is no easy way to sort out the positive and negative spatial effects.

The remainder of this paper contains 2 main sections (Methodology and Conclusion). In the Methodological Section, we present some evidence concerning variation in housing prices in relation to proximity to open spaces, initial analyses of the presence of wildlife in Haifa (Israel) and of the complexity of estimating the impact of the positive and negative externalities of nature by means of property values. In the Conclusion Section, we present discussion of our analysis and suggestions for future research.

\section{METHODOLOGY}

\subsection{Open spaces and property values}

Open spaces in cities serve as habitats of a rich assortment of species. Indeed, the highest species richness is on the fringes of cities and in particular in the sprawling urban neighbourhoods at the outer boundaries of cities (McKinney, 2008). Wealthier neighbourhoods are biologically more diverse (Leong, et al., 2016). The value of disturbed or created, novel ecosystems, and the services that they provide, is the subject of a burgeoning literature (Hobbs, Higgs and Hall, 
2013). Ecosystem services, typically grouped into four broad categories, are crucial for human welfare (Corvalan, Hales and McMichael, 2005. Provisioning services contribute to the production of air, fuel, food and water. Regulating services control climate and diseases. Cultural services contribute to the human spiritual well-being and recreational activities. Supporting services, such as biodiversity, provide a basis for the other three types by enabling ecosystems to function by, for example, nutrient cycles and crop pollination.

There is extensive literature that presents evidence that people are willing to pay for proximity to open spaces and natural areas in order to benefit from these services. There is evidence of a positive premium in housing prices at locations near open and green spaces that are perceived as beneficial and attractive (Daams, Sijtsma and Van der Vlist, 2016; Earnhart, 2006; Irwin and Bockstael, 2001) ${ }^{1}$. Analyses aimed to estimate the effects of open spaces on real estate values have found that in general proximity to these amenities has a positive impact (Conway, et al., 2010; Lutzenhiser and Netusil, 2001). But, the influence of open space amenities on residential prices tends to decline with increasing distance (Asaber and Huffman, 2009; Jim and Chen, 2006). In addition, there is evidence that the quality of open spaces and green areas around certain property matters. For example, the perceived density of tree coverage influences differentially residential values (Netusil, Chattopadhyay and Kovacs, 2010; Mansfield, et al., 2005). In certain locations, not only the immediate surroundings are relevant. The quality of the landscape visible from property impacts positively on its value (Schläpfer, et al., 2015; Bourassa, Hoesli and Sun, 2004).

Extensive evidence points to various wild animal and plant species that are present in urban green and grey spaces (VanDruff and Rowse, 1986; Matthies, et al., 2013; Adams, 2006). There are coyotes in Tucson and Chicago, raccoons Cincinnati, foxes in London, wild boars in Riga, Berlin and Haifa, alligators in Palm Beach, moose and black bears in Montreal, cougars in El Paso, and more. As wildlife presence in cities increases, so does the frequency of human-wildlife conflicts such as direct damage to property, predation of pets, perceived and actual conflicts with residents, the spread of diseases and sanitation issues. While interactions with larger wild mammals tend to be overestimated by the media and the population in terms of frequency, the extent of danger and damage (Adams, 2006, real estate values in the vicinity are affected by the perceived rather than actual wildlife nuisance level.

\subsection{Animals in cities}

Recently we studied the presence of wild animals in the city of Haifa, Israel. The city of Haifa is located on the northern Mediterranean cost of Israel. Hosting about 280,000 inhabitants (ICBS, 2014), it is the third largest city in Israel. Its

\footnotetext{
1 The extant literature ignores the negative externalities of proximity of nature to housing. It is our presumption that the various estimates reported could be the subject to misspecification errors.
} 
urban area covers around $66 \mathrm{~km}^{2}$ (Haifa municipality, 2008) along the slopes of the Mount Carmel, extending from the sea level to an elevation of 450 meters. Its hilly topography is characterized by downward slopes towards the Mediterranean Sea, intertwined by relatively deep and green valleys. These valleys penetrate deeply into the urban built fabric, and, spread out as green fingers within the built environment. They are an integral part of the city's open space network (Toger, et al., 2015). Fig. 1 includes a general view of the city of Haifa. The mountain ridge Carmel runs from the Mediterranean in the North-West, uphill towards the South-East which is the highest point in the area. The northern slope of the mountain is the most heavily urbanized area, and the valleys intertwined among residential areas all over the mountain are clearly discernible.

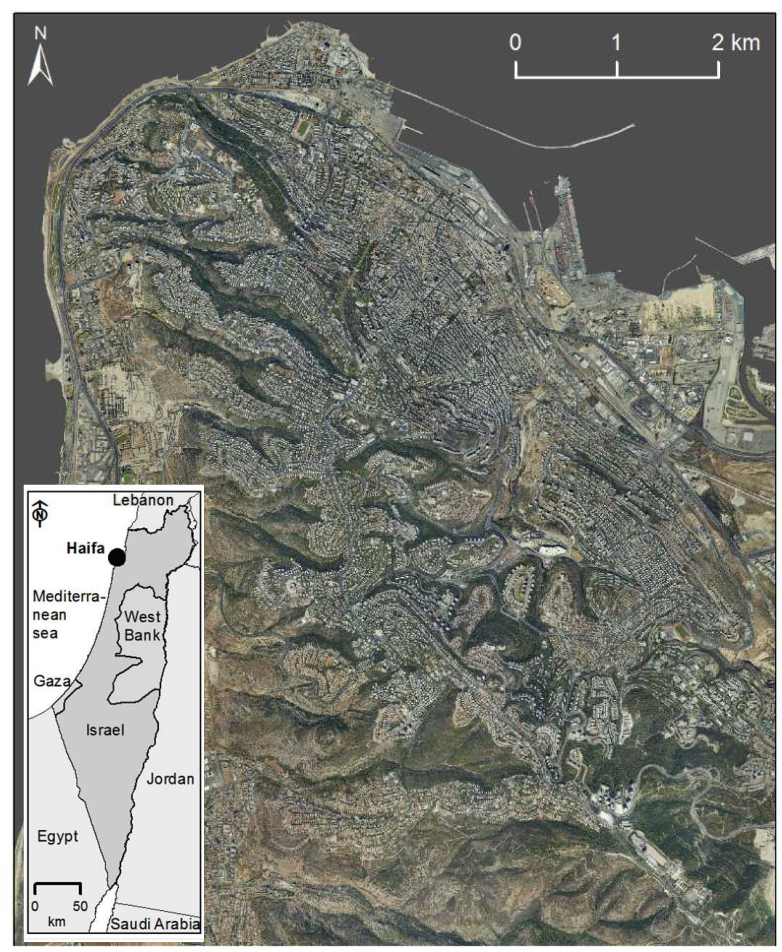

Figure 1-General view of the Haifa area

To study the presence of wild animals, we utilized motion-sensor triggered cameras. Using the same sampling sites as in Matthies, et al. (2013), we observed activity of wild mammals in the open spaces of Haifa. In 2011 we detected 11 wild mammal species, including: golden jackal, Egyptian mongoose, striped hyena, Indian crested porcupine, beech marten, rock hyrax, wild boar, red fox, southern white-breasted hedgehog, European badger, and coypu (Toger, 2016). Jackals and wild boars were observed most frequently. 


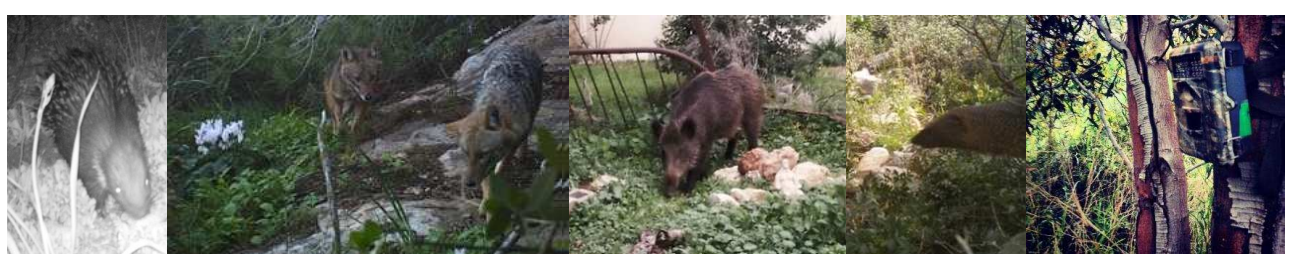

Figure 2 - Animals observed in Haifa using motion-sensor triggered cameras

Boars are frequently seen during night hours foraging for geophytes and acorns in backyards, turning compost and garbage bins upside down. They feature in traffic accidents and are linked to water contamination and spreading of certain diseases such as Escherichia coli, Salmonellosis and Swine influenza (Schierack, et al., 2009). Furthermore, because of their ability to survive in urban areas, boars outcompete some native and endangered species.

While most residents consider them a nuisance, there are those that seize the occasion and enjoy the interaction with nature in an urban environment (Barshaw, 2012). Recently the wild boars (Sus scrofa) received a lot of attention in professional and social media as a token nuisance animal in Haifa. Residents report addresses of observations of wild boars in the city to the municipality. The valleys in Haifa serve as habitat for wild boars as well as other species within the urban areas. In Haifa, as in many other cities, problems related to wild boars were reported in recent years (Cahill, et al., 2012; Licoppe, et al., 2013).

Haifa municipality systematically records observations reported by citizens about nuisances caused by wild boars. We compiled the reported data for the years 2011-2013. The data include address and date of 5,120 observations ${ }^{2}$. Using ArcGIS software (ESRI, 2012), the locations of these observations were geocoded. Since these complaints are the only evidence available about wild boars' location, we used a kernel density smoothing procedure in order to create a continuous surface of assumed "wild boars density function", and then normalized it to a range between 0 and 1. Fig. 3 (left) shows the normalized observed density of wild boars: Darker colours indicate the higher quartile (values between 0.75 and 1 , the maximum), while lighter ones indicate the medium quartiles ( 0.5 to 0.75 and 0.25 to 0.5$)$. The lower quartile and places where wild boars were not observed are not indicated in the map (blank areas).

In addition, we calculated a map of wild boars penetrable and impenetrable areas in Haifa. Using high resolution patterns of open spaces connectivity, we apply the concept of cost of animal movement in the city (Rudnick, et al., 2012) to calculate the impenetrability variable. The impedance (cost) to animal movement is defined as a combined measure representing disturbance from human infrastructures (roads, buildings, fenced areas, etc.) and energy expenditure of the animal. We relate it to the land-use/land-cover type, the most frequently used environmental variable in connectivity analysis studies (Zeller, McGarigal and

\footnotetext{
${ }^{2}$ The raw data about wild boars observations is a courtesy of Haifa Municipal Veterinary Dr. Y. Weiss.
} 
Whiteley, 2012). The impenetrability variable was calculated as cost-distance (ESRI, 2012) to each point in the city from the closest open space cell over a cost surface. The cost (resistance, movement impedance) surface was derived from land-use/land-cover (LULC) dataset described in Toger, et al. (2015) with the cost of 0 for open spaces; 0.25 for gardens and parks; 0.5 for backyards and squares; 0.75 for roads, railroads and transportation space, and infinite cost for obstacles such as buildings, construction, industry, and water. The cost-distance impenetrability values were normalized to the range between 0 and 1 , with open spaces being completely penetrable (value of 0 ) and obstacles completely impenetrable (value of 1). Fig. 3 (right) shows the results of the calculation. Dark red areas are virtually impenetrable for wild boars, whether because they are hermetically fenced (infrastructures, industries and civil or military facilities) or because they are densely built, and possible boars movement among them is highly improbable, or because they are far from the open spaces thus costdistance value is very high. However, white areas are easily penetrable for wild boars, because of their closeness to open spaces, and, additionally, because the urban fabric in these areas is less dense (private houses, gardens, wider roads, abundance of available corridors, etc.).

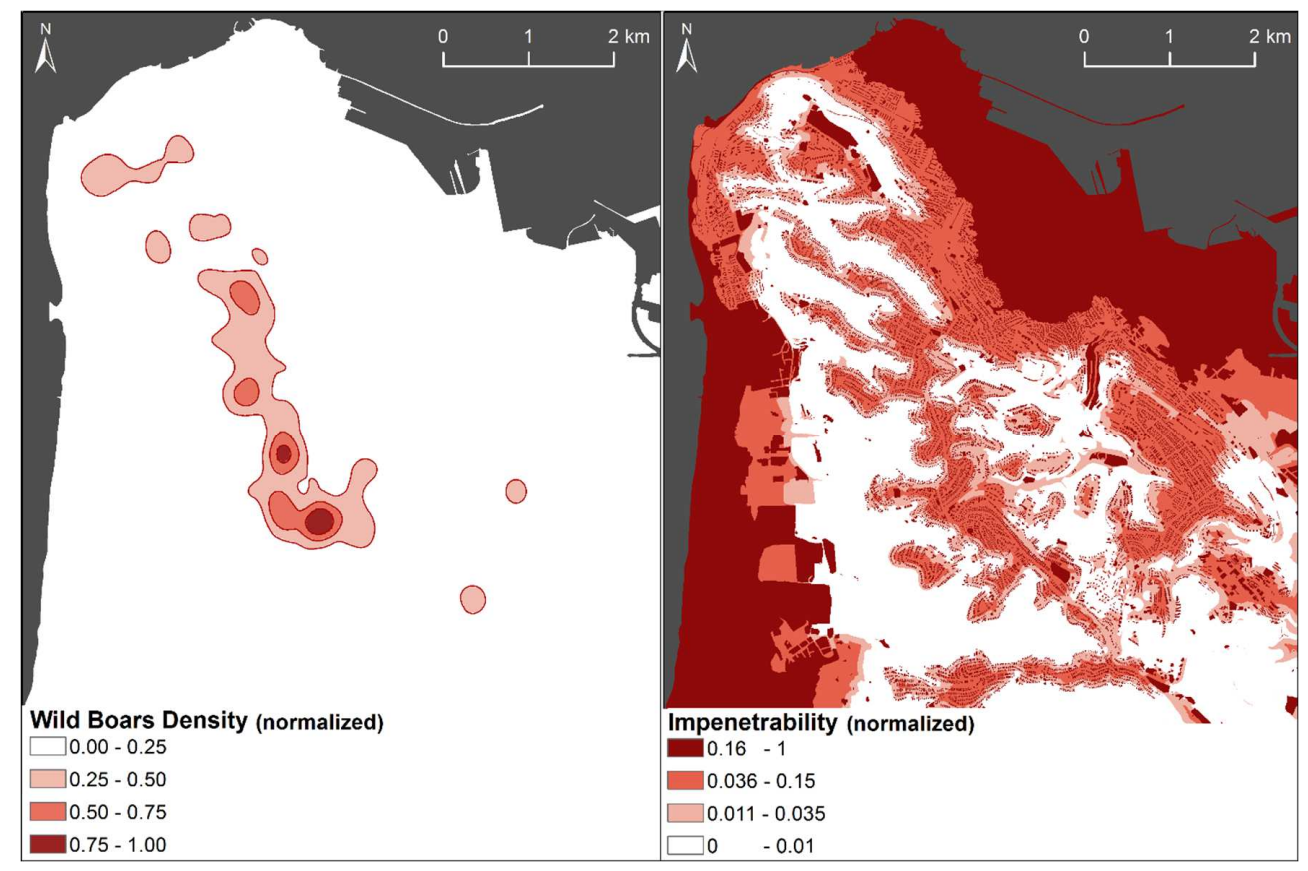

Figure 3 - Normalized observed density of wild boars (left) and penetrable areas for wild boars (right)

A simple visual comparison of fig. 3 right and left suggests that places with higher wild boars observed densities coincide roughly with built and residential zones surrounded by penetrable areas. The intuition is that wild boars penetrate 
into the urban fabric preferentially in locations where a relatively easy retreat into safer open areas is possible.

\subsection{The complex relationship of property prices and nature}

In order to illustrate the relationship of various aspects of proximity to nature and property values, we use a dataset of 22,463 real estate transactions that took place in the city of Haifa during the period 2005-2014. The data include the price per square meter and several details about the properties transacted, such as a number of rooms, surface area and age.

In order to visualize the spatial morphology of residential prices in Haifa, we use again a kernel density smoothing procedure. We created a continuous and normalized surface with values between 0 and 1. Fig. 4 (left) presents the results. The highest dwelling prices quartile is located in the lower-right quadrant of the map, coincident with the highest topographic altitude of the urban fabric and the Mount Carmel. This area is also near one of the largest national parks in Israel, the Carmel Park, which limits with the city precisely there. Along the Mount Carmel ridge, in North-West direction, prices remain high (second and third quartiles), decreasing as the city approaches to the Mediterranean Sea and downwards along the southern and northern slopes. The lowest quartile is not shown in the map, but it includes mainly properties located along the shore, both in the West and in the North, where large infrastructures (roads, railways and harbors) are located.

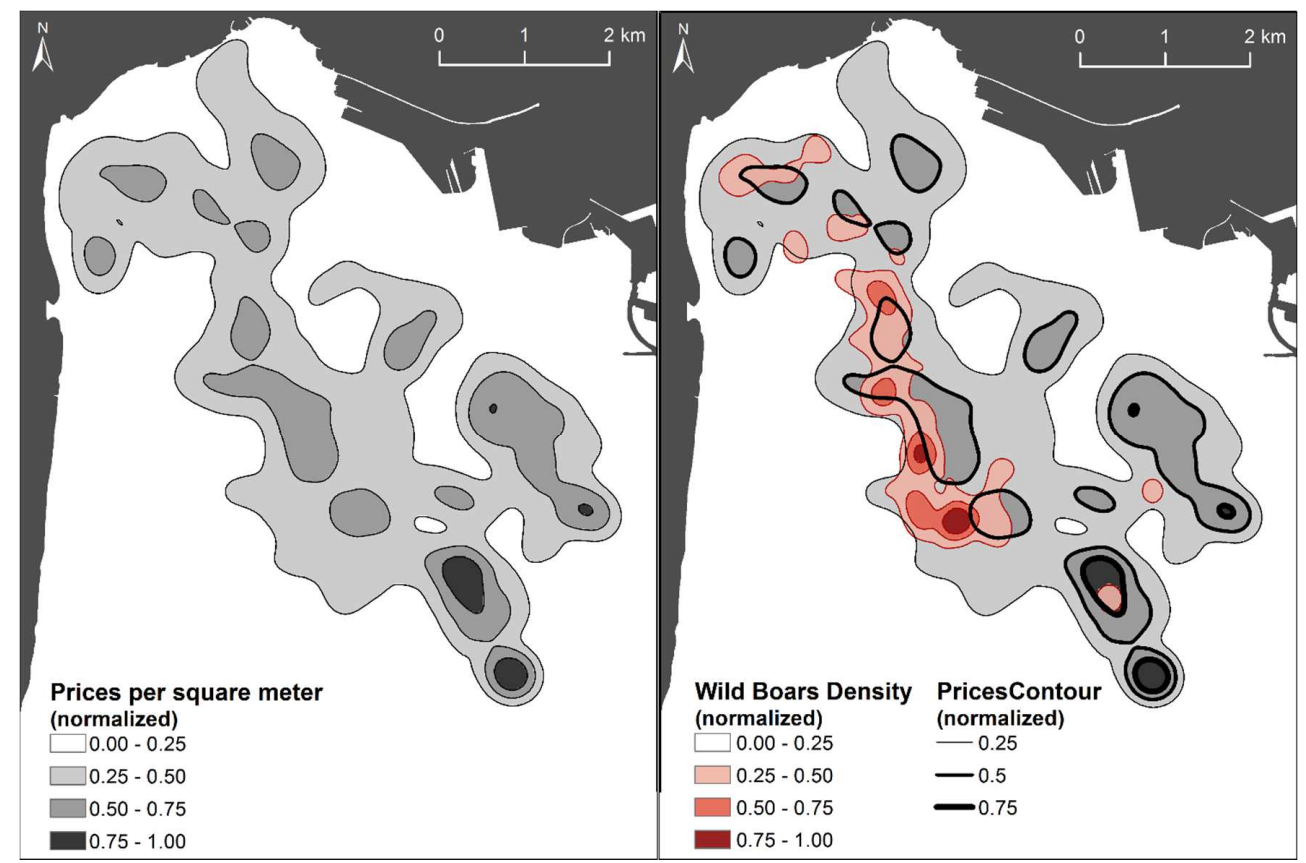

Figure 4 - Property prices (left) and overlap of wild boars' density and property prices (right) 
We hypothesize that places with the intensive activity of wild boars are less attractive for urban dwellers, due to their associated nuisances. In order to create a visual feasibility test of our hypothesis, we combine the dwelling prices with the wild boars density in a single map. Fig. 4 (right) combines the features displayed previously in figures 3-left (boars' density) and 4-left (normalized property prices).

Fig. 4 (right) suggests that the presence of wild boars is insignificant in neighbourhoods with extremely low property prices. Only in neighbourhoods with property values in the upper three price quartiles, wild boars activity is high and generates significant volumes of complaints. At the same time, and as is evident from fig. 3, wild boars' presence is related to proximity to open spaces and to deep valleys in particular. Thus, the locations that are attractive for humans are attractive to wild boars as well. Humans prefer aesthetic and recreational values of these locations and boars seek available food in areas that are easily accessible to them. It is noteworthy that places with low property values are characterized by a lack of open and green spaces and by limited landscape quality and closeness to industrial and transport infrastructure. These are the factors that make them unattractive for wild boars, and therefore little or no activity is recorded there.

But, the correlation between locations that are highly attractive to humans and to boars is not perfect. The relationship is far from being simple. The highest price quartile areas, located at the South-East corner of the map (Fig. 4, darker black spots), do not coincide with the highest quartile of the wild boars density, located about $1.5 \mathrm{~km}$ North-East (the darker red spots). We presume that low intensity of boars does not constitute a problem for residents and does not affect the demand for housing. The impact on demand and prices of housing requires that the presence of boars exceed some unknown threshold values.

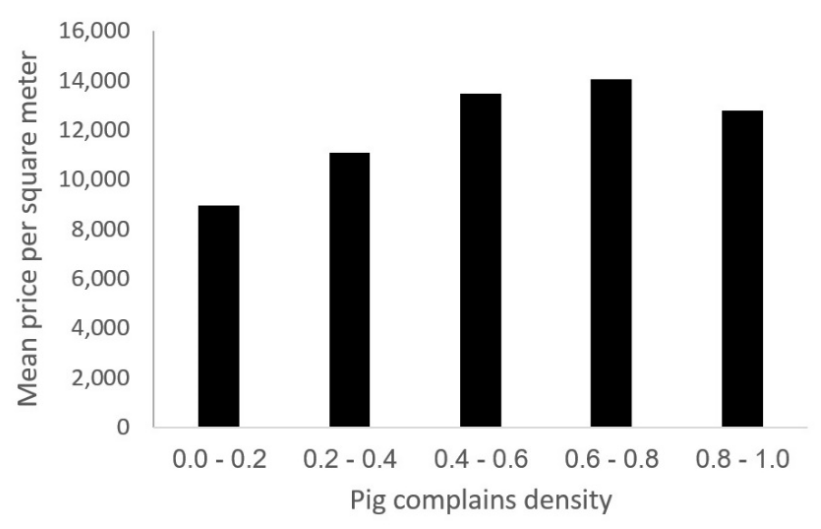

Figure 5-Mean price per $m^{2}$ as function of wild boars' density

Real estate transactions can be grouped according to their location in different wild boars density areas. Since wild boars density spans between 0 and 1 , this 
variable can be divided in five sections of equal range. The ample majority of the transactions $(21,494$ out of 22,462$)$ are located in areas almost unaffected by wild boars (range $0.0-0.4$ ). Only the tiny minority of the transactions belongs to areas where the influence of wild boars is expected to be significant (968 out of $22,462)$. For each transactions group, we can calculate the descriptive statistics of its prices per square meter. Fig. 5 graphically shows the mean price per square meter as a function of wild boars' density.

The mean price per square meter increases steadily together with the boars' density. The first three columns in figure 5 indicate that the price increases by more than $20 \%$. The transition from range $0.4-0.6$ to $0.6-0.8$ is more moderated (an increase of around $4 \%$ ). However, when crossing to range 0.8-1.0 the trend changes suddenly and the price per square meter drops dramatically by almost $9 \%$.

Analysing real estate transactions according to their location and wild boars density areas reveals important differences between two main groups. The majority of these transactions $(21,494$ out of 22,462$)$ occurred in areas with low wild boars impact (density range between 0.0-0.4). However, from the point of view of our research question, interesting phenomena should be found precisely in transactions located in places heavily influenced by boars. Focusing on the remaining $4 \%$ of the dataset, we discovered that, related to that specific subset, the average price per square meter is lower than the average price found in its immediate surroundings (see fig. 5). Although this is not a demonstration that intensive wild boars presence pushes down property values, the analysis performed here suggests that there are good reasons to believe that there might be a connection between wild boar presence and lower property prices.

\section{CONCLUSION}

The well and widely documented higher willingness to pay for properties located near open spaces within cities is considered an expression of the positive externalities from nature experienced by urbanites. But as we illustrated here, in some cases, physical proximity to natural areas may be the source of negative externalities as well. These may result from nuisances caused by wild animals. Using data about property prices and wild boars' observations, we conclude that there are good reasons to suggest that this is the case in Haifa, Israel. However, disentangling mixed positive and negative effects of proximity to nature in urban areas is a complex task due to several types of challenges. At first sight, it seems that the same factors that attract humans to certain areas make them attractive for the wild boars too: nearby green and open spaces, abundant vegetation, closeness to valleys, etc. In addition, residential areas surrounded by wild boar habitat, become even more attractive to the boars because of the abundance of available food and the safety of nearby natural areas. 
Assuming that a simple procedure for disentangling positive and negative effects could be conceived, an additional methodological challenge is posed by the fact that wild animals' nuisance effects are not necessarily linear. It seems that, in order to be perceived as a nuisance, wild animal's presence has to be noticeable, continuous and create some type of damage. Using different functions to model positive and negative effects may complicate the statistical model, but still, modelling curvilinear variables can shed light on the presumably non-linear relations between animal's presence and the nuisances caused by them. A simple solution would be to try different data transformations of one or both measurement variables and then perform a linear correlation of the transformed data. A more elaborated option is to explore the fit of a curvilinear regression using functions as exponential, power or logarithm. Other concerns relate to the quality of the data. Wild boar presence data used here are based on reports by citizens. One would expect fewer reports where there are less people. Boars observed in unexpected locations are more likely to get reported. In residential areas during work hours the probability of boar reports is lower. Moreover, the probability of boars being reported depends on population density per area which is heterogeneous.

It should be noted that our approach is conceptually different from the urban environmental perspective. Instead of focusing on the positive and negative influences of cities on their natural physical environments (as for example in Camagni, Capello and Nijkamp, 1998) we are interested in positive and negative influences of urban nature on urbanites' welfare. Our original contribution is to deal empirically with ecological disservices from nature, which affect negatively urban dwellers.

Despite the methodological issues in an effort to disentangle positive and negative externalities, the evidence we present suggests that estimates of the premium that people are willing to pay for proximity to green spaces may be the result of misspecification error. We cannot suggest at present whether the estimates should be bigger or smaller than reported in the literature (e.g. Bertram and Rehdanz, 2015). Given the methodological and policy challenges of sorting the complex interactions between cities and nature, there is a need for further research.

\section{ACKNOWLEDGMENTS}

We would like to thank Dr. Danny Ben-Shahar for providing the property transactions data, Dr. Dan Malkinson for providing the boar sightings data and the Israel Science Foundation, grant number 949/15, for partial funding. 


\section{REFERENCES}

Adams, C.E., Lindsey K.J. and Ash, S.J., 2006. Urban wildlife management. Boca Raton, FL: CRC Press.

Asaber, P.K. and Huffman, F.E., 2009. The relative impacts of trails and greenbelts on home price. Journal of Real Estate Finance and Economics, 38(4), pp.408-419.

Barshaw, D., 2012. Rotten Hogs!. The times of Israel. [online] 30 March 2012. Available at: <http://blogs.timesofisrael.com/rotten-hogs/> [Accessed 10 February 2017].

Benguigui, L., Czamanski, D. and Marinov, M., 2001a. City growth as a leapfrogging process: an application to the Tel Aviv metropolis. Urban Studies, 38(10), pp.1819-1839.

Benguigui, L., Czamanski, D. and Marinov, M., 2001b. The Dynamics of urban morphology: the case of Petah Tikvah. Environment and planning B: Planning and design, 28(3), pp.447-460.

Benguigui, L., Czamanski, D. and Marinov, M., 2004. Scaling and urban growth. International Journal of Modern Physics C, 15(07), pp.989-996.

Benguigui, L., Czamanski, D., Marinov, M. and Portugali, Y., 2000. When and where is a city fractal?. Environment and planning B: Planning and design, 27(4), pp.507-519.

Bertram, C. and Rejdanz, K., 2015. The role of urban green space for human well-being. Ecological Economics, 120, pp.139-152.

Bourassa, S.C., Hoesli, M. and Sun, J., 2004. What's in a view?. Environment and Planning A, 36(8), pp.1427-1450.

Cahill, S., Llimona, F., Cabañeros, L. and Calomardo, F., 2012. Characteristics of wild boar (Sus scrofa) habituation to urban areas in the Collserola Natural Park (Barcelona) and comparison with other locations. Animal Biodiversity and Conservation, 35(2), pp.221-233.

Camagni, R., Capello, R. and Nijkamp, P., 1998. Towards sustainable city policy: an economy-environment technology nexus. Ecological economics, 24(1), pp.103-118.

Conway, D., Li, C.Q., Wolch, J., Kahle, C. and Jerrett, M., 2010. A spatial autocorrelation approach for examining the effects of urban greenspace on residential property values. The Journal of Real Estate Finance and Economics, 41(2), pp.150-169.

Corvalan, C., Hales, S. and McMichael, A.J., 2005. Ecosystems and human wellbeing: health synthesis: a report of the Millennium Ecosystem Assessment. Washington, D.C.: Island Press. 
Czamanski, D., Malkinson, D. and Toger, M., 2014. Nature in Future Cities: Prospects and a Planning Agenda. Built Environment, 40(4), pp.508-520.

Daams, M.N., Sijtsma, F.J. and Van der Vlist, A.J., 2016. The Effect of Natural Space on Nearby Property Prices: Accounting for Perceived Attractiveness. Land Economics, 92(3), pp.389-410.

Earnhart, D., 2006. Using contingent-pricing analysis to value open space and its duration at residential locations. Land Economics, 82(1), pp.17-35.

ESRI, 2012. ArcGIS Desktop Release (10.1). [Computer program] Redlands, CA: Environmental Systems Research Institute.

Haifa Municipality, 2008. Existing status report for Haifa master plan HP2000. [pdf] Haifa Municipality. Available at: $<$ http://www1.haifa.muni.il/mitar/chapters/chap3.pdf $>$ [Accessed 10 February 2017].

Hobbs, R.J., Higgs, E.S. and Hall, C., 2013. Novel ecosystems: intervening in the new ecological world order. New York: John Wiley and Sons.

ICBS, 2014. Haifa, 2014. [online] Available at: <http://www.cbs.gov.il> [Accessed 12 July 2016].

Irwin, E.G. and Bockstael, N.E., 2001. The problem of identifying land use spillovers: measuring the effects of open space on residential property values. American journal of agricultural economics, 83(3), pp.698-704.

Jim, C.Y. and Chen, W.Y., 2006. Impacts of urban environmental elements on residential housing prices in Guangzhou (China). Landscape and Urban Planning, 78(4), pp.422-434.

Leong, M., Bertone, M.A., Bayless, K.M., Dunn, R.R. and Trautwein, M.D., 2016. Exoskeletons and economics: indoor arthropod diversity increases in affluent neighbourhoods. Biology Letters, 12(8), 5p.

Licoppe, A., Prévot, C., Heymans, M., Bovy, C., Casaer, J. and Cahill, S., 2013. Wild boar/feral pig in (peri-) urban areas. [pdf] Brussels, Belgium: Congress of International Union of Game Biologists IUGB 2013. Available at: $<$ http://www.wildlife-man.be/docs/urban-wild-boar-international-survey.pdf> [Accessed 10 February 2017].

Lutzenhiser, M. and Netusil, N.R., 2001. The effect of open spaces on a home's sale price. Contemporary Economic Policy, 19(3), pp.291-298.

Mansfield, C., Pattanayak, S.K., McDow, W., McDonald, R. and Halpin, P., 2005. Shades of green: measuring the value of urban forests in the housing market. Journal of Forest Economics, 11(3), pp.177-199.

Matthies, S., Kopel, D., Rüter, S., Toger, M., Prasse, R., Czamanski, D. and Malkinson, D., 2013. Vascular Plant Species Richness Patterns in Urban Environments: Case Studies from Hannover, Germany and Haifa, Israel. In: D. 
Malkinson, D. Czamanski and I. Benenson, eds. 2013. Modeling of Land-Use and Ecological Dynamics. Berlin Heidelberg: Springer. pp.107-118.

McKinney, M.L., 2008. Effects of urbanization on species richness: a review of plants and animals. Urban ecosystems, 11(2), pp.161-176.

McPhearson, T., Pickett, S.T., Grimm, N.B., Niemelä, J., Alberti, M., Elmqvist, T., Weber, C., Haase, D., Breuste, J. and Qureshi, S., 2016. Advancing urban ecology toward a science of cities. BioScience, 66(3), 15p.

Netusil, N.R., Chattopadhyay, S. and Kovacs, K.F., 2010. Estimating the demand for tree canopy: a second-stage hedonic price analysis in Portland, Oregon. Land Economics, 86(2), pp.281-293.

Niemelä, J., 1999. Ecology and urban planning. Biodiversity and conservation, 8(1), pp.119-131.

Rudnick, D., Ryan, S.J., Beier, P., Cushman, S.A., Dieffenbach, F., Epps, C., Gerber, L.R., Hartter, J., Jenness, J.S., Kintsch, J. and Merenlender, A.M., 2012. The role of landscape connectivity in planning and implementing conservation and restoration priorities. Issues in Ecology, 16(Fall), pp.1-20.

Schierack, P., Römer, A., Jores, J., Kaspar, H., Guenther, S., Filter, M., Eichberg, J. and Wieler, L.H., 2009. Isolation and characterization of intestinal Escherichia coli clones from wild boars in Germany. Applied and environmental microbiology, 75(3), pp.695-702.

Schläpfer, F., Waltert, F., Segura, L. and Kienast, F., 2015. Valuation of landscape amenities: A hedonic pricing analysis of housing rents in urban, suburban and periurban Switzerland. Landscape and Urban Planning, 141, pp.24-40.

Toger, M., 2016. Urban open spaces: network morphology, dynamics and influence on wildlife foraging in Haifa. Ph.D. Technion - Israel Institute of Technology.

Toger, M., Benenson, I., Czamanski, D. and Malkinson, D., 2015. The connectivity of the Haifa urban open space network. Environment and Planning B: Planning and Design, 43(5), pp.848-870.

Tzoulas, K., Korpela, K., Venn, S., Yli-Pelkonen, V., Kaźmierczak, A., Niemela, J. and James, P., 2007. Promoting ecosystem and human health in urban areas using Green Infrastructure: A literature review. Landscape and urban planning, 81(3), pp.167-178.

VanDruff, L.W. and Rowse, R.N., 1986. Habitat association of mammals in Syracuse, New York. Urban Ecology, 9(3-4), pp.413-434.

Zeller, K.A., McGarigal, K. and Whiteley, A.R., 2012. Estimating landscape resistance to movement: a review. Landscape Ecology, [e-journal] 27(6), pp.777 - 797. http://dx.doi.org/doi:10.1007/s10980-012-9737-0. 


\section{ABOUT AUTHORS}

Dani Broitman is a researcher at the Faculty of Architecture and Town Planning of the Technion - Israel Institute of Technology. E-mail contact: danib@technion.ac.il.

Danny Czamanski is the head of the economics department at the Western Galilee College. E-mail contact: danny@czamanski.com.

Marina Toger is a researcher at the Faculty of Architecture and Town Planning of the Technion - Israel Institute of Technology. E-mail contact: lizardie@gmail.com.

(C) 2017 by the authors. Submitted for possible open access publication under the terms and conditions of the Creative Commons Attribution (CC-BY) license (http://creativecommons.org/licenses/by/4.0/). 